\title{
The Relevance Of Management Information System (Mis) For Decision-Making In Management Strategic Framework Of Enterprises
}

\section{${ }^{1}$ Camila Silva Sousa, ${ }^{2}$ Jesse Monteiro Vieira Junior, ${ }^{3}$ Rosimeire Freires Pereira Oliveira, ${ }^{4}$ Sidney dos Santos Oliveira, ${ }^{5}$ Ananélia Claudia Rodrigues de Queiroz Albuquerque}

\author{
${ }^{1}$ Faculdade Estácio Amazonas. Av. Djalma Batista, Chapada-Manaus - Amazonas - Brasil. (cfss.camila@gmail.com) \\ ${ }^{2}$ Faculdade Estácio Amazonas. Av. Djalma Batista, Chapada-Manaus - Amazonas - Brasil. \\ ${ }^{3}$ Faculdade Estácio Amazonas. Av. Djalma Batista, Chapada-Manaus - Amazonas - Brasil. (rosimeirefpol@yahoo.com.br) \\ ${ }^{4}$ Secretaria de Educação e Desporto-SEDUC-Manaus- Amazonas-Brasil (sidneyoliveira54@ yahoo.com.br) \\ ${ }^{5}$ Centro Universitário de Ensino Superior do Amazonas-CIESA-Manaus- Amazonas-Brasil (ananeliar@bol.com.br)
}

\begin{abstract}
This article presents the importance of the Management Information System - MIS for decision-making in the strategic management of private companies, since the changes are inevitable because of the technological innovations that are now listed on the market. MIS is critical to the success of organizations and help in the administrative area through strategies to use reports that assist in controlling the necessary information for the management and standardization of processes, thus providing increased production, sales, failure reduction in processes and also assists in the implementation of integrated systems. MIS The methodology used was the bibliographical studies, books and articles of renowned authors, the subject matter in this work proved to describe the relevance of MIS, seeking to bring the situations that involve the knowledge and strategies to be applied to continuous improvement of organization. The discussions showed that, after use of MIS all companies should have a control in the most efficient information on all processes of the organization since in possession of information generally becomes practical and efficient administrative management of MIS.
\end{abstract}

Keywords: systems integration, strategy, process excellence.

\section{INTRODUCTION}

This article aims to conceptualize what is the management information system, showing its importance and benefits for companies that adopt MIS as strategic differentiator and as a fundamental tool in decision making and strategic management.

MIS generates information products that support the needs of decision-making, and are the results of the collaborative interactions among people, technology and procedures that help an organization achieve its goals. It is the study of information systems in business and administration, supporting the strategic level through reports, current processes information through the IS (information system), supporting internal diagnosis, SWOT analysis, planning, control and decision.

Given the above came the following issues: What is the relevance of MIS for decision-making in the strategic management of private companies?

The objectives were defined in general: To analyze the relevance of MIS for decision making in the strategic management of private enterprises. And the specific: Identify the importance of MIS for decision-making; Determine their strengths and weaknesses; Understand their relevance and assess their level of importance to decision making.

Several private companies err in not having control of your information and processes through a proper system to help in this task, thus creating many problems in organizations, so the MIS within companies is strategic so that the activities can be performed with the due support and excellence within the company.

It is understood that the use of MIS within the company demonstrates is of great importance, because the main objective is to demonstrate the clarity of information through clear reports with accurate information that is essential for management to produce results increasingly positive and effective.

\section{METHODOLOGY}

The research was a qualitative approach. Considering the research classification criteria proposed by [1], and the technical procedures used for their development, that is, as to the means, the research was the bibliographical, and was carried out 
from the survey of theoretical references in books, in order to gather information or prior knowledge, to analyze the various positions on the problem of research.

\section{MIS AND ITS PECULIARITIES}

MIS is the development and use of information systems that help companies achieve their goals and objectives [2]. MIS is a data transformation process into information that is used in the operative structure of the company, providing the administrative support for optimization of the expected results.

The system can be defined as a group of interrelated elements or interaction that forms a unified whole [3]. It is a set of interacting and interdependent parts that form a system with specific functions, guided in the management information [4].

In accordance with the aforementioned authors note the importance of MIS IS for effective control of management information using the daily reports with monitoring of business processes.

\section{The MIS comprises in:}

Data Entry: is the release of all data generated in the organization, and the development of their usual activities; Processing is the process of transformation of thousands of generated data (organizing, highlighting and selecting exceptions) into useful information in decision making; Data Output: is the manifestation of all that has been processed and will be the foundation for managerial and strategic decisions. It is noteworthy that some output data may return the system input for a feedback to refine the order and evaluate the input data [5].

It is understood that the activities are groups of related tasks that receive data / information processing with an order to produce results. The system can be seen as a set of functions logically structured, in order to meet certain goals, since every company is composed of several systems totaling an microsystem, thus the company itself is a static structure.

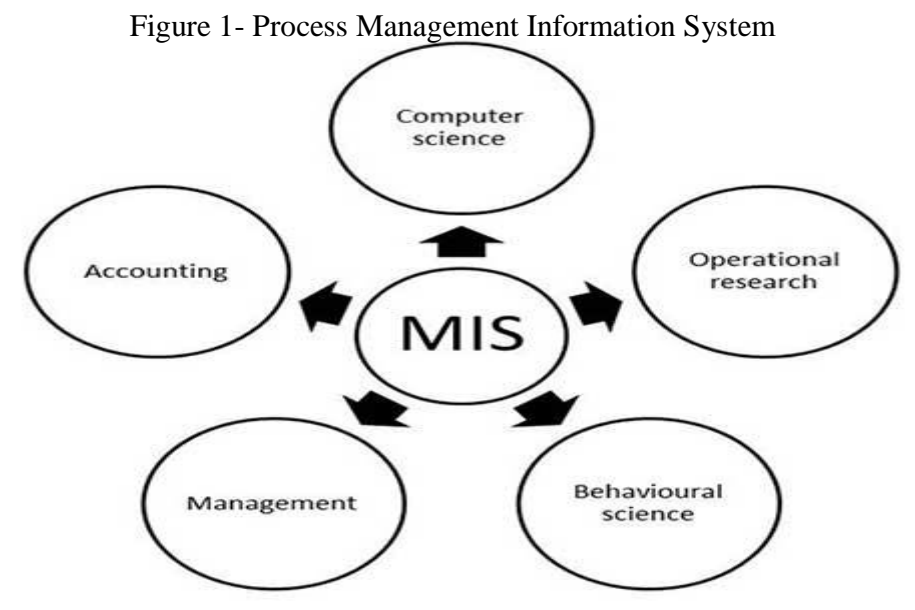

Source: Zaccarelli, (2012).
Note that the use of the system moves the structure and dynamics, and is formed by the set of information systems, or the range of elements produced by codes, to enable planning, organization, coordination and control of operations in a process. Another important observance is the ecosystem that is the whole, being formed by the subsystem or part thereof. Already the subsystem are the parties identified in a structured manner, integrating the system [4].

For [6] is the largest, both in the arena and in scope, or more complete, and can also be called supersystem, which include the whole environment that makes up the organization. Considering that the system is part, that is, subsystem ecosystem. This division of the system in question are structured and identified parts, components organs, theme members, piece of matter in question.

Can be equal to a usual process, consisting of data entries and information outlets, also other so that no errors occur at the end result, for this it needs to be replenished. There are two types of systems, open and closed. The open system is one that suffers influences of the environment that surrounds their actions and influence this environment. But the closed system does not suffer influences of the environment or changes to internal actions [7].

The closed system is insulated, airtight, independent of environmental approaches which is inserted. Companies with its business units and its business functions cannot be seen as a closed system, so they can run incalculable risks and generate big losses for them. In the open enterprise system, there are exchanges with the external environment and changes involving their strategies and require planning that interacts with the advances, allowing its existence.

Note that for decision making to be effective, it is necessary to understand that information is one of the most valuable resources of an organization. This term, however, is often confused with data.

The data consists of facts that have not gone through a preparation, which represent the real world [8]. Since any element in its raw form that alone does not lead to an understanding of a particular event or situation [4]. The basic items of information before being processed by a system that feed the input [9].

The synopsis data is understood as information elements, set of letters, numbers, digits, which took alone, convey no knowledge, it does not contain a clear meaning.

Beforehand information is an organized set of facts in such a way that have additional value beyond the value of the individual events [8]. Data are configured properly to understand and use by humans [7].

Information is given working that allows the executive to make decisions. Can be seen as the results of data processing, 
produced leaving the system, whether manual or computer, that is, information is all given working, useful, treated, with significant value assigned to it with natural and logical sense for anyone who uses the information.

For decision making, should work with the processed information and not data [7]. The data itself is the smallest decomposition of an element to the information that matters to the decision maker, information is the basic element of systems.

Transforming data into information is a process, or a set of logically related tasks performed to achieve a defined result. The process of defining relationships between the data to create useful information requires knowledge. Knowledge is the awareness and understanding of a range of information and how this information can be useful to support a specific task or to reach a decision. Having knowledge means understanding the relationships of information.

It is understood that the information is "worked", that is, through the transformation process and enables the generation of scenarios, simulations and opportunities that can be called knowledge.

Therefore, the information system can assist the manager in decision making; namely, that the knowledge can not be confused with decisions (mental acts, thoughts), with shares (physical acts, plays) or procedures. For example: go to the bank; add the values; calculate the interest; pay the bill. It is observed that whenever a verb in the infinitive is necessary to characterize a decision or action [10].

Every method that manipulates data and generates communication can be generically considered information system.

The MIS is a data transformation process into information that is used in the operative structure of the company and provide administrative support, aiming to optimize the expected results. Information system (IS) is an organized group of people, hardware, software, communication networks and data resources that collects, transforms and disseminates information in an organization [3].

It is generally agreed, both in business and in society, the SI make up one of the largest and most valuable data processing assets that generate information. The information is well managed is a positive point for the manager in their decisions.

Management processes are translated into information systems in order to improve the internal control of the company and its response time to all market fluctuations, allowing for more effective decision making.

The SIG also called support system to business management and management systems, includes the data processing groups of operations and operational transactions, transforming them into information grouped for management. Working with grouped data (or systematized) of business operations and assist decision-making [6].

The leverage that the company can achieve through proper MIS is highly significant, because it may represent a significant result with organizational goals.

In charge GIS provides several tools consisting of an integrated system that gathers information and generates reports specific, accurate data and results, taking control of the entire set of information. A variety of information products, which are presented through reports that help managers by providing data and information to assist in decision making.

According to [4], The systems have some reports that are used by the MIS, such as: scheduled report: It is a traditional way of providing information to managers. Typical reports are the daily and weekly or monthly financial statements sales.

Exception report: Are exceptional case reports where the manager can get specific information. For example, a credit manager may receive a report that contains information only on customers who exceed credit limits. Information and answers the request: This type of report shows information whenever the manager request. Which allows through their workstations immediate answers. Battery Reports: Information is stacked on the network workstation and accessed by management.

\section{THE DECISION-MAKING PROCESS}

Decision making is the identification of a specific problem and choosing a course of action in the search for solution [11].

The decision-making process is the method of choosing a course of action among several alternatives to solve a problem; effective choice can have a strong impact on the performance of the unit and across the organization.

A problem can be defined as a normal or abnormal situation, which must be examined and treated according to their complexity, thus defining the problem and solving it becomes a matter of survival for the whole organization [12].

The basic feature of the strategy problem is the discrepancy, which is the existence opponents with unpredictable reactions. If the opponent had predictable reactions, then the problem would go to the field of logic and should therefore be resolved [13].

Since that problem is everything that is outside the established and blocks the achievement of the expected results, a problem can be a good opportunity to be seized. Opportunity is a 
situation that occurs when circumstances offer a chance for the organization exceed its stated objectives.

Administrators are faced with many difficulties, they need to recognize really what the problems are and what the opportunities are. Generally recognize the existence of a problem is the first step to recognize the existence of an opportunity.

Depending on the nature of the situation, the administrator must use different types of decisions. The degree of information availability accurate and reliable on the situation and the organizational level at which decisions are made distinguishes two types of management decisions: decisions scheduled and unscheduled [14].

It is observed that a well-structured, routine and repetitive decision is known as programmed and unstructured is called unscheduled. Companies today are embedded in a highly competitive environment that demands efficiency levels ever higher. The effectiveness of an organization, translated by its economic results, occurs as all decisions seek to optimize their results. For the effective decisions is needed "a broad knowledge of reality" brought about by the information for decision making.
Thus, the manager can take decisions scheduled and unscheduled addition to heuristics to solve problems. According to [15], the phases of a decision-making process itself, as well as the implementation of decisions requires seven steps: Perception of situation involving a problem; Analysis and definition of the problem; Definition of objectives; Looking for alternative solutions or courses of action; Select (check) the most appropriate alternative to achieve the objectives; Evaluation and comparison of alternatives and implementation of the chosen alternative.

The decision model from the perspective of strategic management, and induce efficiency, allows the performance of managers is assessed according to their contribution to the generation of the overall result of the organization. It is important to eliminate the problems in the cause, root, through good SIG is expected that the agent decision maker, has certain skills and competencies that distinguish and enable them to overcome constant challenges.

Information systems become prevalent, to establish forms and update mechanisms, enabling decision making fits within criteria and more rational basis and less emotional and situational. Not that the leader should only make decisions based

GeoMIS : Geospatial Managemonpunflgrmation \&łstlards, but it has the perspective and the conditions to establish a risk assessment, based on criteria

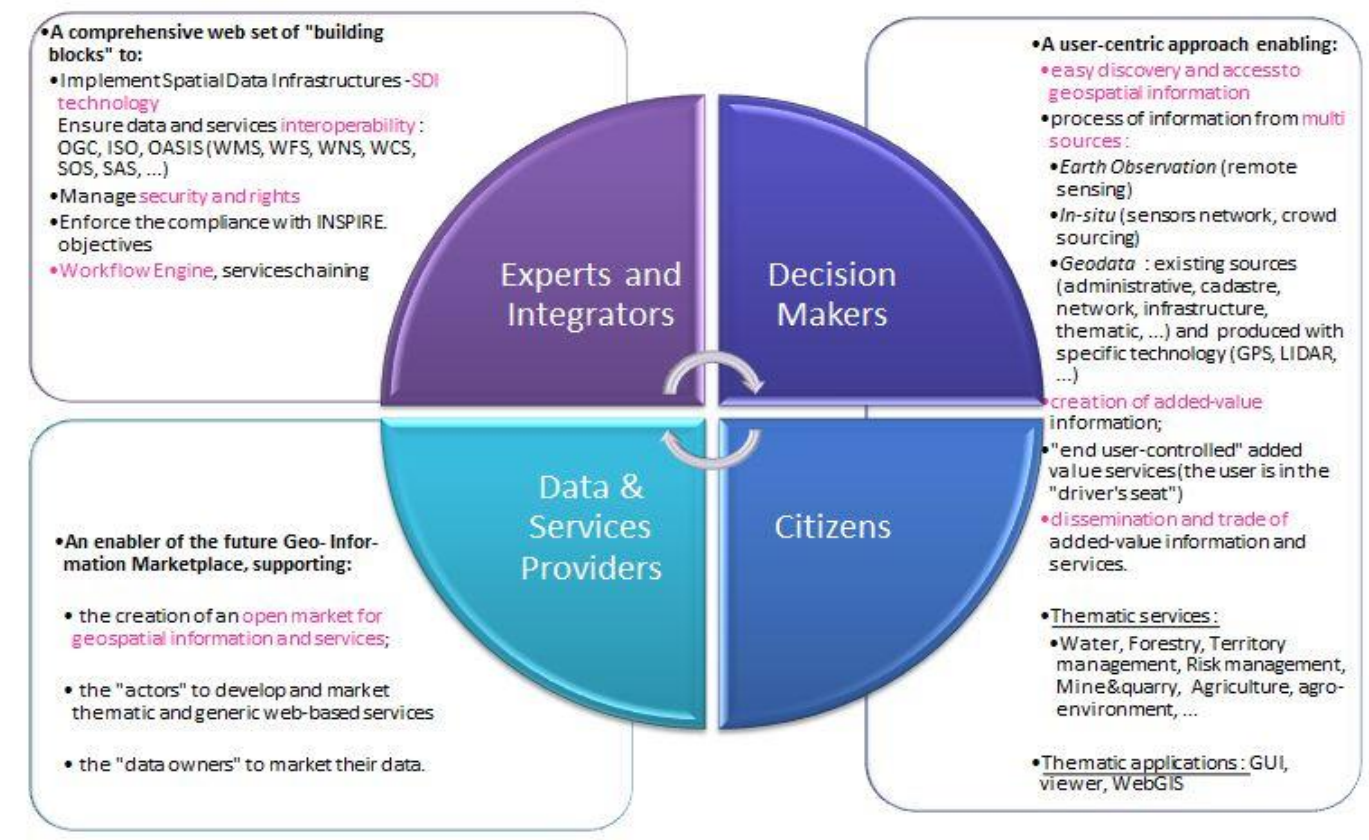

Figure 2- Geospatial Management Information System.

Source: Zaccarelli, (2012).
The decision making process is comprised of steps in which one depends upon the other and occurs in environments uncertainties. involving a certain subjectivism, through information systems, are possible assessment and risk reduction. 


\section{THE RELEVANCE OF MIS IN DECISION MAKING IN THE STRATEGIC MANAGEMENT}

SIG also called the organizational management support system works grouped data operations, supporting the decision making of the departments, in synergy with the other units. In short the system is any process that manipulates grouped information, or interconnected with intent to decision-making. MIS is the development and use of information that help business systems to achieve their goals and objectives [2].

In agreement with Kroenke future business professionals need the ability to estimate, evaluate and apply the business information technology that is in innovation every day, producing values that affect positively or negatively. management information systems by definition serve as a basis for the functions of planning, control and decision making at the management level. [7].

According to the criteria of decision support, classification of information systems can be: operational, managerial and strategic [10]. classification of choosing a good alternative based on the generation of several scenarios information [6].

DSS's comprise a class of information extracted from transaction processing systems systems and interact with other parts of the support of the executive principle to underpin decision making of managers and other managers of the company.

A synopsis SOAD has the potential to become a powerful tool in set of professional features to help increase the effectiveness of people in business, contemplating higher productivity. That in agreement with the DSS potentiate effectiveness in continuous improvement using MIS as the SAD aid. Information systems can be in solving tools. Several factors are important for problem solving and awareness of these factors increase the appropriately analyze manager capacity the problem and make effective decisions.

Still according to Rezende, the information can be considered as a differential when it provides alternative returns, solidifying the current activities or creating new opportunities. Benefit performance of internal MIS: Support for strategic planning, support for management control and support for operational control. External: product quality improvement and improved product distribution.

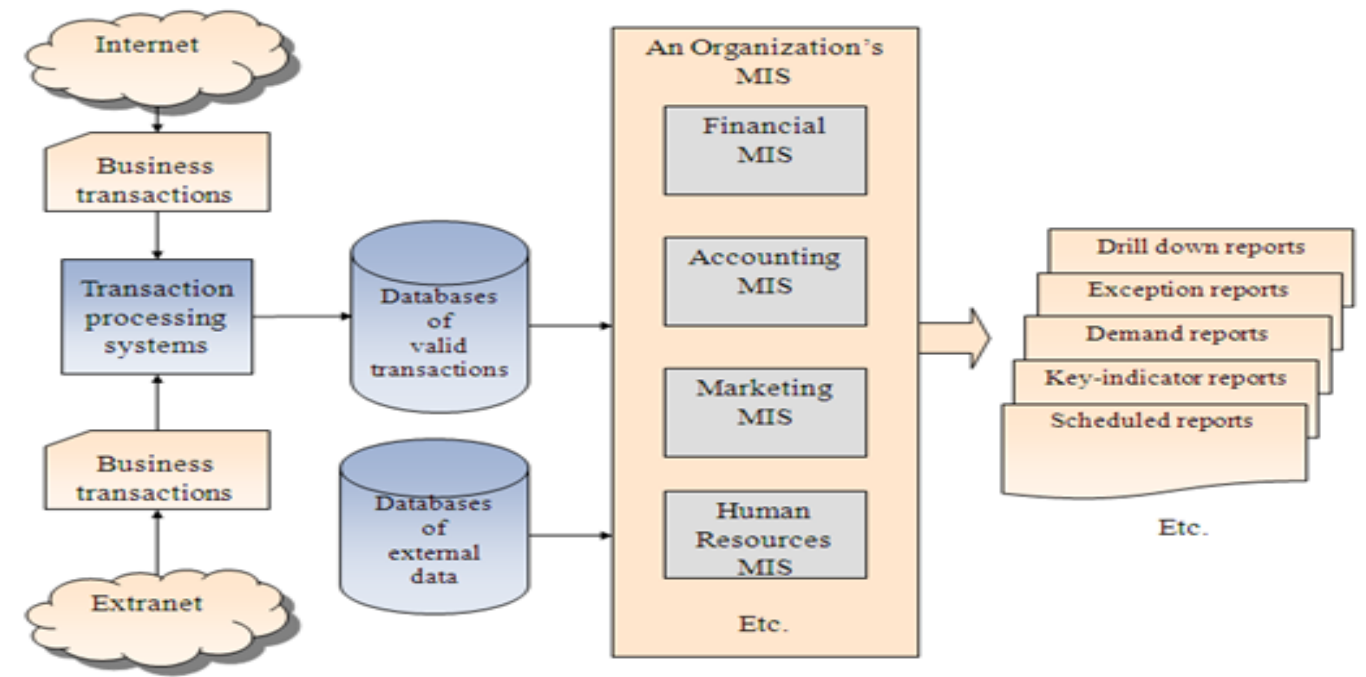

Figure 3- Operation Management Information System.

Source: STAIR, (2011).

The levels of information and business decision obey the existing standard hierarchy in most companies, also called corporate pyramid and are known as strategic, tactical and operational.

MIS and Decision Systems Support (DSS) are key technologies for the evolution of the decision-making process in business, help the executive at all stages of decision making, especially in the development stages, comparison and
Decision makers need to SI to ensure them certain strategic positioning failure to use the SI may cause future losses [16].

If all executions take place using the decisions of which information is the basic input, the management of information is of vital importance to the proper functioning of the process. 


\section{FINAL CONSIDERATIONS}

The paper describes the research objectives, overlapping that all management functions, planning, organization, direction and control are necessary for the proper organizational performance, MIS, so it is important to assist in decision making.

One can say that GIS is an integral part of business strategies, due to the communication and information that create value in organizations.

The quality of the decision taken by the manager will depend on the degree of information acquired.

It is important to invest in a MIS to provide fast, accurate and most useful, that will guarantee a structure of differentiated management, which will result in competitive advantage over other companies.

In summary, MIS is necessary so that there is greater efficiency in decision-making to achieve and achieve organizational goals.

\section{AGRADECIMENTOS}

Ao Instituto de Tecnologia e Educação Galileo da Amazônia (ITEGAM), ao PPGEP do Instituto de Tecnologia Universidade Federal do Pará (ITEC-UFPA) e a Universidade Estácio de Sá pelo apoio financeiro a pesquisa.

\section{REFERENCES}

[1] VERGARA, S. C. Tipos de pesquisa em administração. Cadernos EBAP - Fundação Getúlio Vargas, Rio de Janeiro, v. 1, n. 52, p. 1-11, 1990.

[2] KROENK, D. M. Sistemas de informações gerenciais. São Paulo: Saraiva, 2012, 307 p.

[3] O' BRIEN, J. A. Sistemas de informação e as decisões gerenciais na era da internet. 3. ed. São Paulo, 2010, 431 p.

[4] OLIVEIRA, D. P.R. Sistemas de informações gerenciais: estratégicas, táticas, operacionais. 15. ed. São Paulo: Atlas, 2012, 299 p.

[5] BATISTA, E. O. Sistemas de informação. 2. ed. São Paulo: Saraiva, 2014, 358 p.

[6] REZENDE, D. A. ABREU, A. F. Tecnologia da informação - aplicada a sistema de informação empresarial. 7. ed. São Paulo: Atlas, 2010, 303 p.

[7] ROSINI, A. M. Administração de sistemas de informação e a gestão do conhecimento. 2. ed. São Paulo: Cengage Learning, 2012, 212 p.
[8] STAIR, R. M., REYNOLDS, G. W. Princípios de sistemas de informações. 9. ed. São Paulo: Cengage Learning, 2011, 590 p.

[9] CASSARRO, A. C. Sistemas de informações para tomadas de decisões. 4. ed. São Paulo: Cengage Learning, 2010, 120 p.

[10] REZENDE, D. A. Sistemas de informações organizacionais: guia prático para projetos em cursos de administração, contabilidade e informática. 5. ed. São Paulo: Atlas, 2013, 143 p.

[11] STONER, J. A. F. Administração. 5. ed. Rio de Janeiro: LTC, 2012, 533 p.

[12] OLIVEIRA, J. F; et al.. Liderança: Uma questão de competência. 1. ed. 4 tiragem. São Paulo: Saraiva, 2011, 366 p.

[13] ZACACARELLI, S. B. Estratégia e sucesso nas empresas. 2. ed. São Paulo: Saraiva, 2012, 249 p.

[14] SOBRAL, F.; PECI, A. Administração: teoria e prática no contexto brasileiro. 2. ed. São Paulo: Pearson Education do Brasil, 2013, 611 p.

[15] CHIAVENATO, I. Introdução à teoria geral da administração. 8. ed. Rio de Janeiro: Elsevier, 2011, 608 p.

[16] GURGEL, C.; RODRIGUES, M. V. Administração elementos essenciais para a gestão das organizações. 2. ed. São Paulo: Atlas, 2014, 270 p. 